University of Nebraska - Lincoln

DigitalCommons@University of Nebraska - Lincoln

2-23-2004

\title{
Surface photovoltage effects on the isomeric semiconductors of boron-carbide
}

\author{
A. N. Caruso \\ University of Nebraska-Lincoln, carusoan@umkc.edu \\ Snjezana Balaz \\ University of Nebraska-Lincoln, sbalaz@ysu.edu \\ Bo Xu \\ University of Nebraska-Lincoln \\ Peter A. Dowben \\ University of Nebraska-Lincoln, pdowben@unl.edu \\ A.S. McMullen-Gunn \\ University of Nebraska-Lincoln \\ See next page for additional authors
}

Follow this and additional works at: https://digitalcommons.unl.edu/physicsdowben

Part of the Physics Commons

Caruso, A. N.; Balaz, Snjezana; Xu, Bo; Dowben, Peter A.; McMullen-Gunn, A.S.; Brand, Jennifer I.; Losovyj, Yaroslav B.; and Mcllroy, D.N., "Surface photovoltage effects on the isomeric semiconductors of boroncarbide" (2004). Peter Dowben Publications. 8.

https://digitalcommons.unl.edu/physicsdowben/8

This Article is brought to you for free and open access by the Research Papers in Physics and Astronomy at DigitalCommons@University of Nebraska - Lincoln. It has been accepted for inclusion in Peter Dowben Publications by an authorized administrator of DigitalCommons@University of Nebraska - Lincoln. 


\section{Authors}

A. N. Caruso, Snjezana Balaz, Bo Xu, Peter A. Dowben, A.S. McMullen-Gunn, Jennifer I. Brand, Yaroslav B. Losovyj, and D.N. Mcllroy 


\title{
Surface photovoltage effects on the isomeric semiconductors of boron-carbide
}

\author{
A. N. Caruso, Snjezana Balaz, Bo Xu, and P. A. Dowben ${ }^{\mathrm{a})}$ \\ Department of Physics \& Astronomy and the Center for Materials Research and Analysis (CMRA), Behlen \\ Laboratory of Physics, University of Nebraska-Lincoln, Lincoln, Nebraska 68588-0111 \\ A. S. McMullen-Gunn and J. I. Brand \\ College of Engineering, University of Nebraska-Lincoln, Lincoln, Nebraska 68588-0511 \\ Y. B. Losovyj \\ Center for Advanced Microstructures and Devices, Louisiana State University, Baton Rouge, Louisiana 70806 \\ D. N. Mcllroy \\ Department of Physics, University of Idaho, Moscow, Idaho 83844-0903
}

(Received 15 August 2003; accepted 18 December 2003)

\begin{abstract}
During exposure to synchrotron radiation, closo 1,7-dicarbadodecaborane (metacarborane) and closo 1,2-dicarbadodecaborane (orthocarborane) decompose, and are accompanied by increasingly evident photoemission surface photovoltage effects. We show that metacarborane and orthocarborane form self-doped $n$-type and $p$-type boron-carbides, respectively. Surface photovoltage effects dominate the photoemission final state, not the changes in electronic structure due to decomposition. (C) 2004 American Institute of Physics. [DOI: 10.1063/1.1648136]
\end{abstract}

Since the recognition of surface photovoltage (SPV) on semiconductors, ${ }^{1}$ the technique has been much exploited. ${ }^{2}$ Surface photovoltage effects with temperature, substrate doping, and metal deposition dependence ${ }^{3-5}$ have been observed by ultraviolet photoemission spectroscopy. While photoemission induced surface photovoltage (SPV) on semiconductors is a well recognized phenomenon, ${ }^{2}$ examples of SPV accompanying the transition from molecular film to semiconductor have not been generally well documented. We have utilized SPV to investigate the formation of the selfdoping isomer dependent semiconductors of boron-carbide.

By exploiting the observation that many molecules ${ }^{6-10}$ including the closo-dicarbdodecaboranes ${ }^{11-13}$ exhibit rigid band character and little band bending, the onset of a surface photovoltage, in photoemission, is a key indicator of semiconductor formation (and type) from molecular decomposition. Band bending, as a result of charge at the surface and/or defect states, can be compensated during photoemission, due to a surface photovoltage. For $p$-type materials, the electronic structure (the binding energies of the various photoemission features) is observed to shift toward lower binding energy or the valence band shifts toward the $E_{F}$ (Fermi level). For $n$-type semiconductors, the electronic structure shifts toward higher binding energy or the valence band shifts away from $E_{F}$. When the source molecules closo 1,2dicarbadodecaborane (orthocarborane) and closo 1,7dicarbadodecaborane (metacarborane), shown inset to Figs. 1 and 2, are decomposed by synchrotron light (or electron beam induced decomposition), forming two of the many $\mathrm{C}_{2} \mathrm{~B}_{10}$ polytypes of boron-carbide, ${ }^{14}$ respective shifts toward lower and higher binding energy are incurred.

The closo 1,2-dicarbadodecaborane (orthocarborane)

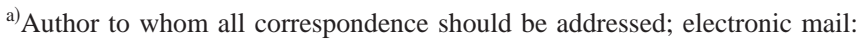
pdowben@unl.edu
}

and closo 1,7-dicarbadodecaborane (metacarborane) molecular films were prepared by adsorption of sublimed vapor (admitted to the vacuum system through standard leak valves) onto substrates cooled to $\sim 105 \mathrm{~K}$. Films of thickness $10-40$ molecular monolayers were adsorbed so as to exceed the elastic photoelectron mean free path. The substrates include the $\mathrm{Cu}(100), \mathrm{Au}(111)$, and polycrystalline $\mathrm{Ag}$ surfaces.

The photoemission spectroscopy measurements were performed at the Center for Advanced Microstructure and Devices in Baton Rouge, LA. The photoemission spectra for orthocarborane on $\mathrm{Cu}$, metacarborane on $\mathrm{Au}$, and both metaand orthocarborane on $\mathrm{Ag}$ were taken at 25,32, and $65 \mathrm{eV}$, respectively, as described elsewhere. ${ }^{11-13}$ For the inverse photoemission studies, all electrons were incident normal to the surface.

Decomposition of the source molecules was initiated and undertaken through the use of the zero-order diffraction (white synchrotron light) though the $3 \mathrm{~m}$ toroidal grating where photon fluxes were on the order of $10^{19}$ photons $/ \mathrm{cm}^{2} / \mathrm{s}$. For the inverse photoemission studies, the source molecules were decomposed by electron beam irradiation. A wealth of characterization suggests that the resulting boron-carbide semiconductor materials, from both electron beam and synchrotron radiation assisted decomposition, are very similar. ${ }^{15,16}$ During decomposition, the exopolyhedral hydrogen is removed from the carborane molecules.

The transition from $\mathrm{C}_{2} \mathrm{~B}_{10} \mathrm{H}_{12}$ (carborane) to $\mathrm{C}_{2} \mathrm{~B}_{10}$ (boron-carbide) is indicated in combined photoemission and inverse photoemission studies by a small HOMO (highest occupied molecular orbital) to LUMO (lowest unoccupied molecular orbital) gap closure. This gap closure is small, relative to the surface photovoltage effect. Although the electronic structure with metacarborane and orthocarborane molecular adsorption is substrate dependent, the spectra with 


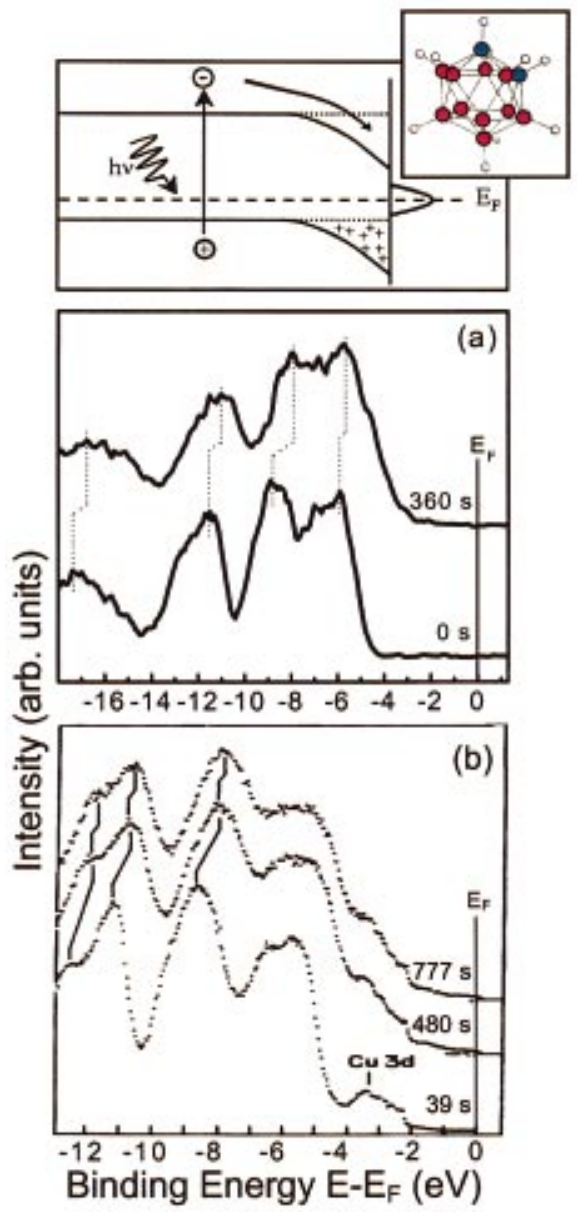

FIG. 1. (Color) At top: a schematic model of the surface photovoltage effect in photoemission shifting the band edges toward smaller binding energy (dotted line) for a $p$-type semiconductor. Band bending and surface defect states, in the absence of incidence light, are assumed to be present in the surface region, see the text. Progressive valence band photoemission spectra of orthocarborane on silver (a) are shown, differing only by the exposure time to broad spectrum synchrotron radiation (noted in seconds). The photoemission spectra for orthocarborane on copper (b) and with progressive exposure to synchrotron light. Notice that the electronic structure shifts toward lower binding energy with increased decomposition (exposure to synchrotron light). Inset: The icosahedral structure of the source molecule used to create $p$-type boron-carbide, closo 1,2-dicarbadodecaborane (orthocarborane).

adsorption on $\mathrm{Ag}, \mathrm{Au}$, and $\mathrm{Cu}$ are very similar. ${ }^{13}$ Carborane molecular adsorption on cobalt ${ }^{17}$ leads to a greater reduction in the HOMO-LUMO gap, than observed on the noble metal surfaces.

As the source molecules decompose, due to incident synchrotron light, the effect (binding energy shifts) of surface photovoltage increases. As decomposition occurs, the band bending in the forming semiconductor (decomposing molecular film) is partly compensated by surface photovoltage charging. Figure 1 illustrates the photoemission features of orthocarborane on both silver (a) and copper (b) shifting toward lower binding energy with increased exposure to synchrotron radiation. Figure 2 shows the changes in photoemission spectra for metacarborane films adsorbed on $\mathrm{Ag}$ and $\mathrm{Au}$ substrates with increasing decomposition due to incident synchrotron white light radiation. Similarly, decomposition, due to an incident electron beam flux, resulted in binding energies shifts of the density of states maximum in the conDownloaded 05 Sep 2006 to 129.93.16.206. Redistribution subject

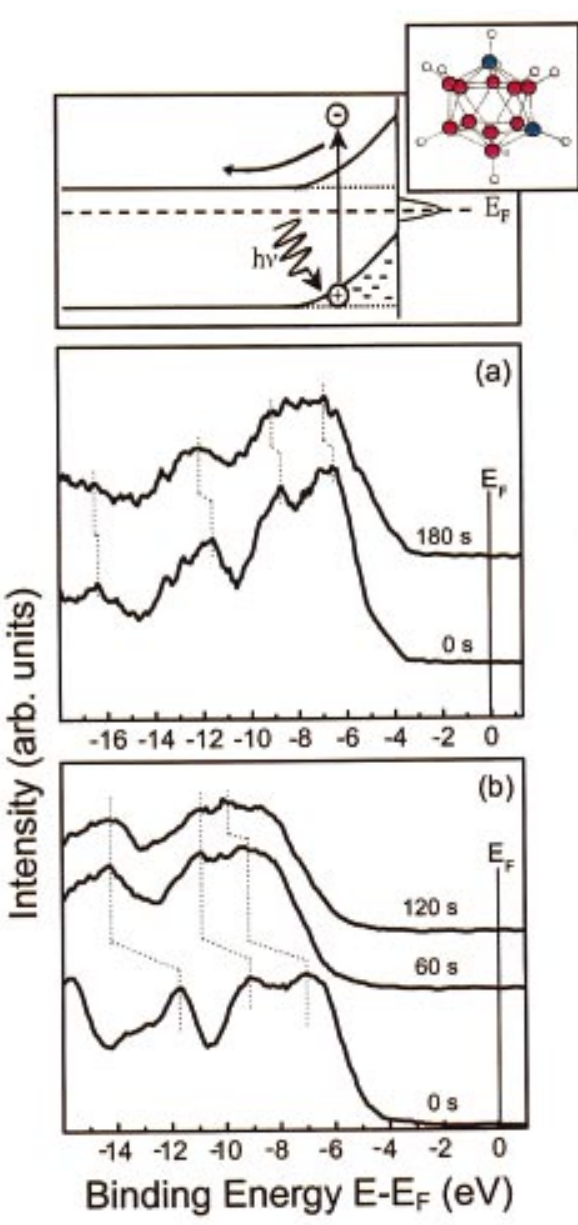

FIG. 2. (Color) At top: a schematic model of the surface photovoltage effect for an $n$-type semiconductor shifting the band edges toward higher binding energy (dotted line). A sequence of valence band photoemission spectra of metacarborane on silver (a) and gold (b), differing only by the exposure time to broad spectrum synchrotron radiation (noted in seconds). Notice the electronic structure shifts toward higher binding energy with increased decomposition (exposure to synchrotron light). Inset: The icosahedral structure of the source molecule used to create $n$-type boron-carbide, closo 1,7dicarbadodecaborane (metacarborane).

duction band of molecular metacarborane, shown by inverse photoemission for metacarborane in the inset of Fig. 3.

Orthocarborane decomposition is indicated by a shift to a lower binding energy and a $p$-type semiconductor is demonstrably formed. ${ }^{18}$ The orthocarborane highest occupied to lowest unoccupied molecular orbital gap of about $11 \mathrm{eV}^{13}$ (as indicated in Fig. 3) should decrease toward the indirect gap of $0.75 \mathrm{eV}^{18}$ with molecular decomposition. A decomposition induced shift should be accompanied by a similar increase in the widths of the photoemission features. Such increases in the photoemission peak widths are not observed here. Surface photovoltage effects must be invoked to explain the binding energy shifts that accompany the decomposition observed. Although the changes are relatively small, the peak widths of the photoemission features discernibly increase with increased decomposition both as a result of the new icosahedral bonding and the final state photoelectron being perturbed by excess photovoltage.

Eventually the SPV reaches a saturation point, wherein all surface acceptor states recombine with secondary electrons for the $p$-type materials, as in the case of boron-carbide formed from the decomposition of orthocarborane, as indi-
to AIP license or copyright, see http://apl.aip.org/apl/copyright.jsp 
cated in the diagram of Fig. 1. In spite of possible HOMOLUMO gap closure due to decomposition of orthocarborane, this does not exceed $1.2 \mathrm{eV}$ shift due to surface photovoltage effects, so we associate this polytype of boron-carbide as being only slightly $p$-type.

In the case of metacarborane decomposition, the binding energy shifts of both the occupied (photoemission, as seen in Fig. 2) and unoccupied states (inverse photoemission, as seen in the inset to Fig. 3) to greater binding energies are indicative of the formation of an $n$-type semiconductor. As the boron carbide is formed from the decomposition of the metacarborane, charge flow to the surface regions is small because of the decreased charge mobility at low temperatures. ${ }^{18}$ Thus in the surface region, the charge tends toward the opposite sign and provides the appearance of band rectification to the flatband condition. Again the photoemission peak widths increase, but again is insufficient to account for the amount of photovoltaic shifting observed. It is the large shift $(>2.5 \mathrm{eV})$ of decomposed metacarborane which indicates that this polytype of boron-carbide is strongly $n$-type and/or a semiconductor with few carriers.

Defect and/or surface state formation is evident, as decomposition occurs, from spectroscopic signatures observed in photoluminescence, ${ }^{18}$ inverse photoemission (as indicated in Fig. 3), and from the inferred band bending. Earlier work using inverse photoemission spectroscopy ${ }^{12}$ provided evidence of a defect state which exists in the highest occupied to lowest unoccupied molecular orbital (HOMO-LUMO) gap, as reproduced in Fig. 3. We note that as hydrogen is lost, not all the $\pi$ orbitals of the $\mathrm{C}_{2} \mathrm{~B}_{10}$ icosahedral cage can be compensated (bonded) by adjacent icosahedra. Defects in the bulk are common, given that in the fully decomposed molecular films, the boron carbide semiconductor crystallite size is about $20 \mathrm{~nm} .{ }^{16,18} \mathrm{In}$ addition, we believe it is the irregular packing of icosahedral building blocks (because pentagons, the two-dimensional projection of the icosahedra, are not space filling) which introduces additional defect states, but it is surface termination which leads to the surface/defect state formation in abundance because of uncompensated bonds. It is the defect and/or surface states which can pin the Fermi level and ultimately determine the extent of band bending.

Decomposition leading to a heterogeneous mixture of decomposition states cannot explain the observed photoemission peak shifts with increased white light induced decomposition. Such heterogeneous decomposition, while leading to closure of the HOMO-LUMO gap, would also be accompanied by very large photoemission peak widths that are not observed, as noted earlier. Thus the prior explanations ${ }^{15,19}$ of the photoemission binding energy shifts, for orthocarborane, as due to HOMO-LUMO gap closure are incorrect.

Two molecules, which only differ by carbon position within the icosahedral cage (orthocarborane and metacarborane), form two very different boron-carbide semiconductors from the differences ${ }^{2,3}$ in surface photovoltage related binding energy shifts in photoemission and inverse photoemission.

This research was supported by the National Science Foundation through Grant Nos. ECS-0300018, EPS0091909, the NSF "QSPINS" MRSEC (DMR-0213808),

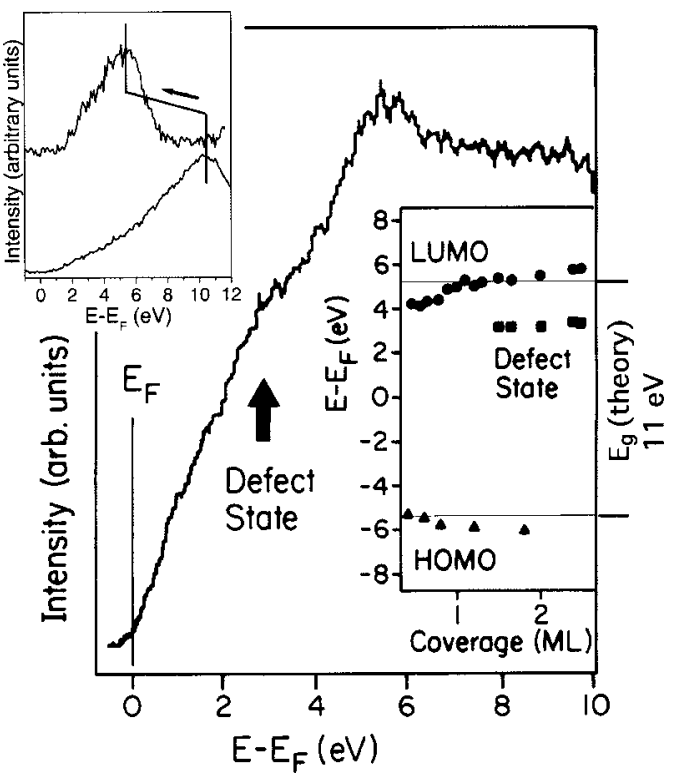

FIG. 3. Inverse photoemission spectra of about 2 monolayers of orthocarborane on copper indicating binding energy position of defect state. The LUMO state is identified from coverage dependence and theory (Refs. 1214). Inset on the bottom right: the experimentally determined HOMOhighest occupied molecular orbital and LUMO_-lowest unoccupied molecular orbital) and defect state dependence with molecular adsorption coverage (the theoretical HOMO-LUMO gap indicated). Because the surface/defect state does not change in binding energy with coverage, this indicates that it is highly localized. The shift to higher binding energy with decomposition of metacarborane is shown in the inset at the top left.

and the Nebraska Research Initiative. The authors would like to thank B. Robertson for a critical reading of the manuscript.

${ }^{1}$ W. H. Brattain and J. Bardeen, Bell Syst. Tech. J. 32, 1 (1953).

${ }^{2}$ D. K. Schroder, Meas. Sci. Technol. 12, R16 (2001).

${ }^{3}$ J. E. Demuth, W. J. Thompson, N. J. DiNardo, and R. Imbihl, Phys. Rev. Lett. 56, 1408 (1986).

${ }^{4}$ M. Alonso, R. Cimino, and K. Horn, Phys. Rev. Lett. 64, 1947 (1990).

${ }^{5}$ K. Stiles and A. Kahn, Phys. Rev. Lett. 60, 440 (1988).

${ }^{6}$ I. D. Parker, J. Appl. Phys. 75, 1656 (1994).

${ }^{7}$ A. R. Brown, D. D. C. Bradley, J. H. Burroughes, R. H. Friend, N. C. Greenham, P. L. Burn, A. B. Holmes, and A. Kraft, Appl. Phys. Lett. 61, 2793 (1992)

${ }^{8}$ B. Xu, A. N. Caruso, and P. A. Dowben, Appl. Phys. A: Mater. Sci. Process. 76, 1 (2003).

${ }^{9}$ B. Xu, J. Choi, A. N. Caruso, and P. A. Dowben, Appl. Phys. Lett. 80, $4342(2002)$

${ }^{10} \mathrm{P}$. A. Dowben, J. Choi, E. Morikawa, and Bo Xu, in Characterization and Spectroscopy of Thin Films, Vol. 2, edited by H. S. Nalwa, Handbook of Thin Films (Academic, New York, 2002) Chap. 2, pp. 61-114.

${ }^{11}$ J. Zhang, D. N. McIlroy, P. A. Dowben, H. Zengi, G. Vidalii, D. Heskett, and M. Onellion, J. Phys.: Condens. Matter 7, 7185 (1995).

${ }^{12}$ D. N. McIlroy, J. Zhang, P. A. Dowben, and D. Heskett, Mater. Sci. Eng., A 217/218, 64 (1996).

${ }^{13}$ A. N. Caruso, L. Bernard, Bo Xu, and P. A. Dowben, J. Phys. Chem. B 107, 9620 (2003).

${ }^{14}$ S. Adenwalla, P. Welsch, A. Harken, J. I. Brand, A. Sezer, and B. W. Robertson, Appl. Phys. Lett. 79, 4357 (2001).

${ }^{15}$ D. Byun, Seong-don Hwang, P. A. Dowben, F. Keith Perkins, F. Filips, and N. J. Ianno, Appl. Phys. Lett. 64, 1968 (1994).

${ }^{16}$ D. Byun, B. R. Spady, N. J. Ianno, and P. A. Dowben, Nanostruct. Mater. 5, 465 (1995)

${ }^{17}$ L. Bernard, A. N. Caruso, Bo Xu, B. Doudin, and P. A. Dowben, Thin Solid Films 428, 253 (2003).

${ }^{18}$ S. Lee, J. Mazurowski, G. Ramseyer, and P. A. Dowben, J. Appl. Phys. 72, 4925 (1992)

${ }^{19}$ D. Byun, S.-D. Hwang, J. Zhang, H. Zeng, F. K. Perkins, G. Vidali, and P. A. Dowben, Jpn. J. Appl. Phys., Part 2 34, L941 (1995). 